\title{
Insulin and muscle amino acid balance
}

By G. F. Cahill Jr, T. T. Aoki, M. F. Brennan and W. A. Müller, From the Joslin Diabetes Foundation and the Department of Medicine and Surgery, Harvard Medical School and the Peter Bent Brigham Hospital, Boston, Mass. 02215, USA

Protein serves several biological functions : locomotion, oncotic pressure, structure, biochemical catalysis, and what is less well emphasized, acts as a storage form of energy. The majority of non-aquatic, mobile animals rely on manoeuverability for survival, and thus the caloric density of lipid places triglyceride synthesis, storage, and mobilization uppermost in the hierarchy of fuel metabolism. In contrast, carbohydrate, as free glucose, or 'protein', as free amino acid, are almost insignificant as fuel resources, as are free fatty acids. More important are stored carbohydrate in glycogen or amino acids in protein, which do provide significant calories, but both of these are accumulated in an aqueous intracellular environment and yield only I-2 kcal $(4-8 \mathrm{~kJ}) / \mathrm{g}$ of tissue, much less than the $6-9 \mathrm{kcal}(25-38 \mathrm{~kJ}) / \mathrm{g}$ as stored triglyceride in tissue.

Thus relatively minimal quantities of glycogen are deposited: in man only a half day's supply of energy, which is conserved for interprandial glucose homoeostasis or for emergency anaerobic fuel. Protein, as far as is known, is only stored in forms serving one of the alternative biological functions. In other words, there is no known protein purely for the sake of storage. With the limited supply of depot carbohydrate and the inability of animal systems to synthesize glucogenic precursor from acetate derived from fatty acid, stored protein serves as the principal glucogenic precursor when carbohydrate or protein are not available from the environment. In man it is muscle protein which appears to be mainly involved in maintaining glucose homoeostasis, and this brief review will discuss the interrelationships of muscle protein, insulin and body carbohydrate and nitrogen economy, with a few comments on a possible role of blood cells in amino acid metabolism.

\section{Fasting and starvation}

As stated above, carbohydrate stores are limited, and after an overnight fast, glucose concentrations are maintained by gluconeogenesis as evidenced by depleted liver glycogen (Hultman \& Nilsson, 1971). Rates of splanchnic glucose output by fasted man vary widely since the transitions from the fed, to the postabsorptive, to the fasted state are associated with a rapidly diminishing glucose output and peripheral uptake. A reasonable estimate, however, is approximately $\mathrm{r} 80 \mathrm{~g} / \mathrm{d}$ (Cahill \& Owen, 1968) of which about one-half is provided by amino acid-derived 
gluconeogenesis. Pozefsky, Felig, Tobin, Soeldner \& Cahill (I969), as had Wiechmann (1924), London, Foley \& Webb (1965) and, more recently, Carlsten, Hallgren, Jagenburg, Svanborg \& Werko (1966), noted the release of amino acids from forearm muscle in fasting man. Permitting much error in the estimation of arterio-venous differences, muscle mass, and flow rates, the release of $\alpha$-amino $\mathrm{N}$ from muscle approximates to what one would need to provide gluconeogenesis to maintain glucose concentrations early in starvation. The remainder of newly synthesized glucose is derived from glycerol released from adipose tissue (about $20 \mathrm{~g} / \mathrm{d}$ ), recycling lactate and pyruvate (about $30-40 \mathrm{~g} / \mathrm{d}$ ) and a small amount from residual liver glycogen. With more prolonged starvation, as concentrations of keto acids increase in the circulation and as brain substitutes keto acids more and more as fuel in place of glucose, gluconeogenic rates decrease as does $\mathrm{N}$ excretion.

Determination of plasma arterio-venous differences of specific amino acids in both brief and prolonged starvation (Felig, Owen, Wahren \& Cahill, I969, Marliss, Aoki, Pozefsky, Most \& Cahill, I97 I) have shown glutamine and alanine to be the predominant constituents (Fig. I). Alanine is derived in part direct from muscle protein and indirectly via transamination from other amino acids, together with pyruvate derived from glucose or possibly from tricarboxylic acid cycle intermediates via small amounts of phosphoenolpyruvate carboxykinase activity located in muscle or both (Opie \& Newsholme, I 967 ). If alanine were formed solely from glucose, no net glucogenic carbon would be provided, since it would require pyruvate derived from glucose. Felig, Pozefsky, Marliss \& Cahill (1970) and Mallette, Exton \& Park (I969)

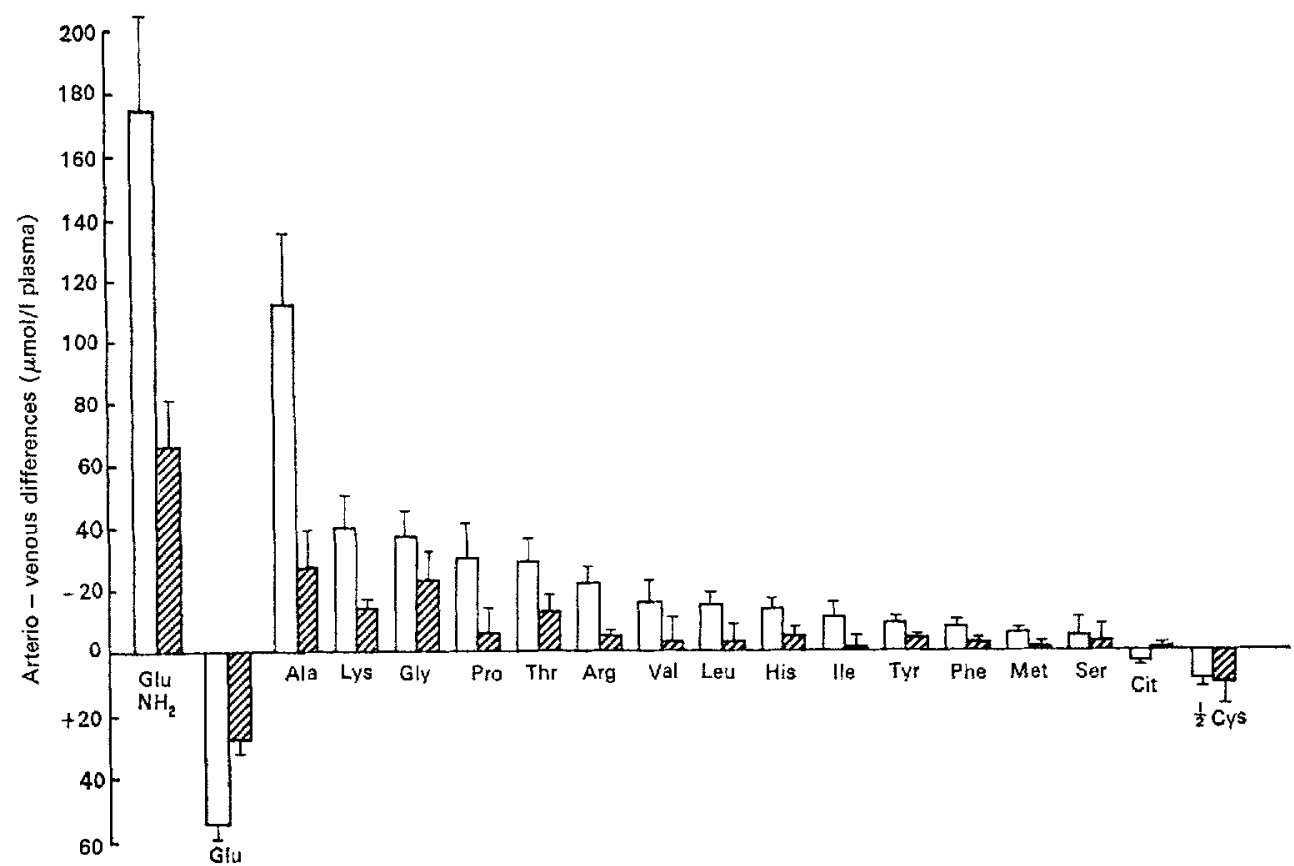

Fig. I. Arterio-venous differences of various amino acids across forcarm muscle in man. $\square$, fasted overnight; $\square$, after $4-6$ weeks of starvation. 
have postulated the pyruvate-glucose-alanine interrelationship as a cycle serving as an ammonia transport mechanism. The glutamine released is partly derived from muscle proteolysis and also from glutamate taken up into muscle and amidated by glutamine synthetase (Iqbal \& Ottaway, I970), with the ammonia coming direct from deamination of branched-chain amino acids or possibly via aspartate by the recently postulated purine nucleotide cycle of Tornheim \& Lowenstein (I97I). In any event, in brief starvation (Fig. I) alanine and glutamine are the amino acids primarily released from muscle into plasma. These still persist as the principal amino acids released even after prolonged starvation, but at a lower rate, and circulating concentrations are reduced accordingly (Aoki, Müller \& Cahill, 1972).

Control mechanisms. Insulin is thought to be the principal and perhaps the sole hormone acutely regulating the rate of muscle proteolysis and amino acid production. This is not surprising, since in any sequence of metabolic reactions, the first irreversible step is usually the site of control. Thus a feedback loop can be constructed whereby circulating concentrations of glucose (and possibly also amino acids) provoke $\beta$-cell release of insulin, and this in turn suppresses muscle proteolysis and the rate of rclease of glutamine and alanine. As glucose concentrations fall, insulin release decreases, insulin concentrations fall and muscle releases glucogenic amino acid. Infusion of small amounts of insulin into fasted man (Aoki, Müller and Cahill, quoted in Cahill, 197I) results in significantly lower concentrations of amino acids, again mainly glutamine and alanine, decreased gluconeogenesis and decreased glucose concentrations. Thus the liver appears to be limited in its gluconeogenic rate not by its enzymatic constituents, but rather by the rate of glucogenic substrate coming from muscle. If this is the situation, raised concentrations of alanine should result in increased glucose concentrations; Felig et al. (1969) have shown this to be so.

Exercise. Clinicians are well aware of the rapid atrophy which occurs in a muscle in an injured limb, or more strikingly when denervation has occurred. Likewise, selective hypertrophy occurs in muscles used excessively, and in the same hormonalsubstrate milieu as the other muscles in the body. Goldberg (I97I) has studied compensatory hypertrophy of the rat soleus after tenotomy of the gastrocnemius and found the hypertrophy to occur even when the animal is starved, meaning that muscle work can override the insulin control of muscle protein. This, again, is not surprising to the clinician who does not find muscle hypertrophy in subjects with excess insulin and, conversely, muscle mass is relatively well preserved in the exercising diabetic as long as there is some insulin, either endogenous or exogenous. Thus insulin integrates the total muscle mass into the glucogenic needs of the body, and each muscle is more or less on its own according to its use and within certain limits as defined by its cellularity. As yet, we have not looked at the rate of fasting amino acid release from human muscle undergoing exercise hypertrophy to see whether it retains more amino acid relative to other muscles in the body not exercised.

Mechanism of insulin action. Several investigators, particularly Cuatrecasas (1969), have shown insulin to exert its metabolic effects by reacting with cell membrane, 
as proven by agarose-bound insulin being capable of eliciting insulin's metabolic effects without gaining access to intracellular fluid. Furthermore, using affinitychromatographic techniques, Cuatrecasas (I97I) has characterized the binding constants of insulin to fat cells and found the $k_{m}$ to be identical to the ambient concentration of insulin found in plasma of fasting animals. From these results one can extrapolate to muscle and form a schematic figure (Fig. 2) whereby lowinsulin concentrations effect muscle proteolysis and amino acid release and highinsulin concentrations provoke synthesis. Recently, Livingstone, Cuatrecasas \& Lockwood (1972) have shown that fat cells from obese animals have the usual marked insulin insensitivity, yet a normal number of receptor sites and a normal binding affinity, suggesting the insulin resistance to be between the receptor site and the physiological response.

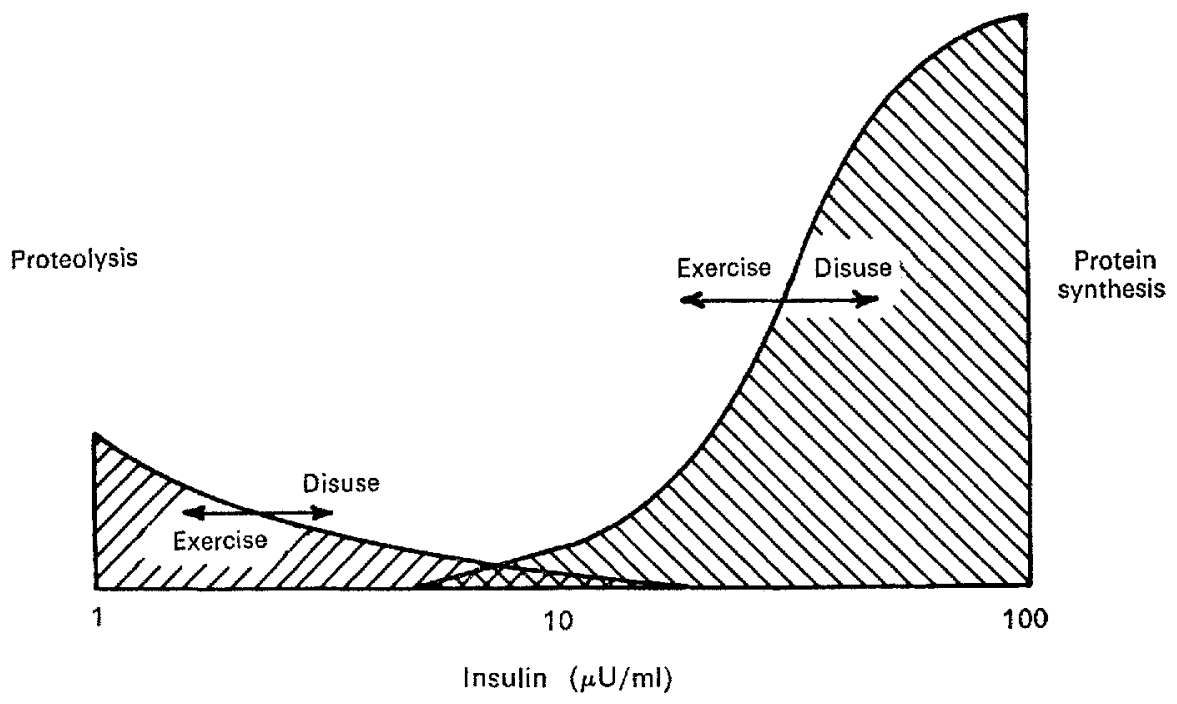

Fig. 2. Schematic representation of interrelationships of excercise and insulin on muscle-protein balance.

How insulin, by reacting with the cell membrane, is capable even in low dosage of inhibiting intracellular proteolysis in muscle, has yet to be understood. In fact, the biochemical reactions initiating proteolysis in any tissue have yet to be clarified. Intravenous administration of small amounts of carbohydrate or insulin to fasting man results in decreased amino acid concentrations, decreased gluconeogenesis and decreased $\mathrm{N}$ excretion, suggesting this anti-proteolytic effect of insulin to be the most sensitive insulin effect in the body (the ' $N$ ' effect of carbohydrate).

\section{Relationship of blood cells and muscle}

Pozefsky et al. (1969) infused insulin locally into forearm muscle of normal man for $26 \mathrm{~min}$ and noted a progressive decrease in the rate of release of $\alpha$-amino $\mathrm{N}$ and most amino acids. A net uptake of amino acids from plasma was not observed. Since amino acids must move back into muscle after meals to replace those lost between 
meals as described above, some restorative process must take place. One possible condition is the need for a rise in plasma amino acid concentration to effect a net movement into muscle. Another possibility is that high-insulin concentrations are needed for a longer period of time, and a third possibility is a role of blood cells in amino acid transport and exchange.

Table I. Effect of local insulin infusion on whole blood and plasma arterio-deepvenous differences in glutamate concentration. Insulin infused between time o and $90 \mathrm{~min}$

(Mean values with their standard errors)

\begin{tabular}{ccc} 
Time & \multicolumn{2}{c}{ Glutamate ( $\mu \mathrm{mol} / 1$ whole blood) } \\
\cline { 2 - 3 } (min) & Whole blood & Plasma \\
0 & $8 \pm 3$ & $23 \pm 1$ \\
60 & $26 \pm 9^{*}$ & $18 \pm 2$ \\
90 & $25 \pm 7^{*}$ & $21 \pm 1$ \\
120 & $24 \pm 9$ & $20 \pm 2$ \\
150 & $18 \pm 6$ & $17 \pm 4$ \\
180 & $13 \pm 7$ & $22 \pm 2$ \\
240 & $4 \pm 8$ & $23 \pm 1$ \\
\multicolumn{3}{c}{}
\end{tabular}

Aoki, Brennan, Müller, Moore \& Cahill (r972) delivered insulin intra-arterially into forearm muscle of normal man for $90 \mathrm{~min}$, raising the insulin concentration to $200 \mu \mathrm{U} / \mathrm{ml}$ (Table $\mathrm{I}$ ). Using an enzymatic procedure for the determination of glutamate, no changes were observed in plasma glutamate arterio-venous differences. However, determination of whole blood glutamate arterio-venous differences revealed a significant uptake of glutamate. When glutamate was analysed independently in plasma and in blood cells it was found that, prior to the insulin infusion, there was a net uptake of glutamate from the plasma into the red cells as the blood traversed the muscle capillary bed. During and after local insulin administration, blood cells and plasma lost glutamate into the tissues. Thus the blood cells, in contrast to what has been previously considered, are not passive in amino acid transport and metabolism. Subsequent studies now in progress have shown other amino acids to be affected by the blood cell-plasma-tissue interchange. Possible abnormalities in this mechanism in pathological states must be examined.

Supported in part by USPHS Grants AM-05077, RF-3I, AM-I 5 I9I, HE-I 3872 , The John A. Hartford Foundation, Inc, and the U.S. Army Research and Development Command DA-49-193-MD-2337. T.T.A. is a USPHS Special Postdoctoral Fellow, M.F.B. a USPHS International Postdoctoral Fellow and W.A.M. a Fellow of the Swiss National Fund.

\section{REFERENCES}

Aoki, T. T., Brennan, M. F., Müller, W. A., Moore, F. D. \& Cahill, G. F. Jr (1972). F. clin. Invest. (In the Press.)

Aoki, T. T., Müller, W. A. \& Cahill, G. F. Jr (1972). Adv. Enzyme Regulation Io, I45.

Cahill, G. F., Jr (197I). Diabetes 20,785 .

Cahill, G. F., Jr \& Owen, O. E. ( 968 ). In Carbohydrate Metabolism and its Disorders p. 497 [F. Dickens, P. J. Randle and W. J. Whelan, editors]. London: Academic Press.

$31(2) \mathrm{x}$ 
Carlsten, A. B., Hallgren, R., Jagenburg, A., Svanborg, A. \& Werko, L. (1966). Acta med. scand. r79, 361 .

Cuatrecasas, P. (1969). Proc. natn. Acad. Sci. U.S.A. 63, 450.

Cuatrecasas, P. (1971). Proc. natn. Acad. Sci. U.S.A. 68, 1264.

Felig, P., Owen, O. E., Wahren, J. \& Cahill, G. F. Jr (1969). F. clin. Invest. 48, 584.

Felig, P., Pozefsky, T., Marliss, E. \& Cahill, G. F. Jr (1970). Science, N.Y. 167, 1003.

Goldberg, A. L. (1971). In Cardiac Hypertrophy p. 39 [N. Alpert, editor]. New York, NY: Academic Press.

Hultman, E. \& Nilsson, L. H. (1971). In Muscle Metabolism in Exercise p. I43 [B. Pernow and B. Saltin, editors]. New York, NY: Plenum Press.

Iqbal, K. \& Ottaway, J. H. (I970). Biochem. \% Ir9, I45.

Livingstone, J. N., Cuatrecasas, P. \& Lockwood, D. H. (I972). Science, N.Y. (In the Press.)

London, D. R., Foley, T. H. \& Webb, C. G. (1965). Nature, Lond. 208, 588.

Mallette, L. E., Exton, J. H. \& Park, C. R. (1969). F. biol. Chem. 244, 5713.

Marliss, E. B., Aoki, T. T., Pozefsky, T., Most, A. J. \& Cahill, G. F. Jr (I971). F. clin. Invest. 5o, 8 I 4 .

Opie, L. H. \& Newsholme, E. A. (1967). Biochem. F. 103, 391.

Pozefsky, T., Felig, P., Tobin, J. D., Socldner, J. S. \& Cahill, G. F. Jr (I969). F. clin. Invest. 48, 2273.

Tornheim, K. \& Lowenstein, J. M. (1971). 7. biol. Chem. 247, 162.

Wiechmann, E. (1924). Z. ges. exp. Med. 44, 158. 